\title{
Evaluation of Crystalline Silica Exposure during Fabrication of Natural and Engineered Stone Countertops
}

Leonard M. Zwack, ScD Kerton R. Victory, PhD, MSc

Scott E. Brueck, MS, CIH Chaolong Qi, PhD

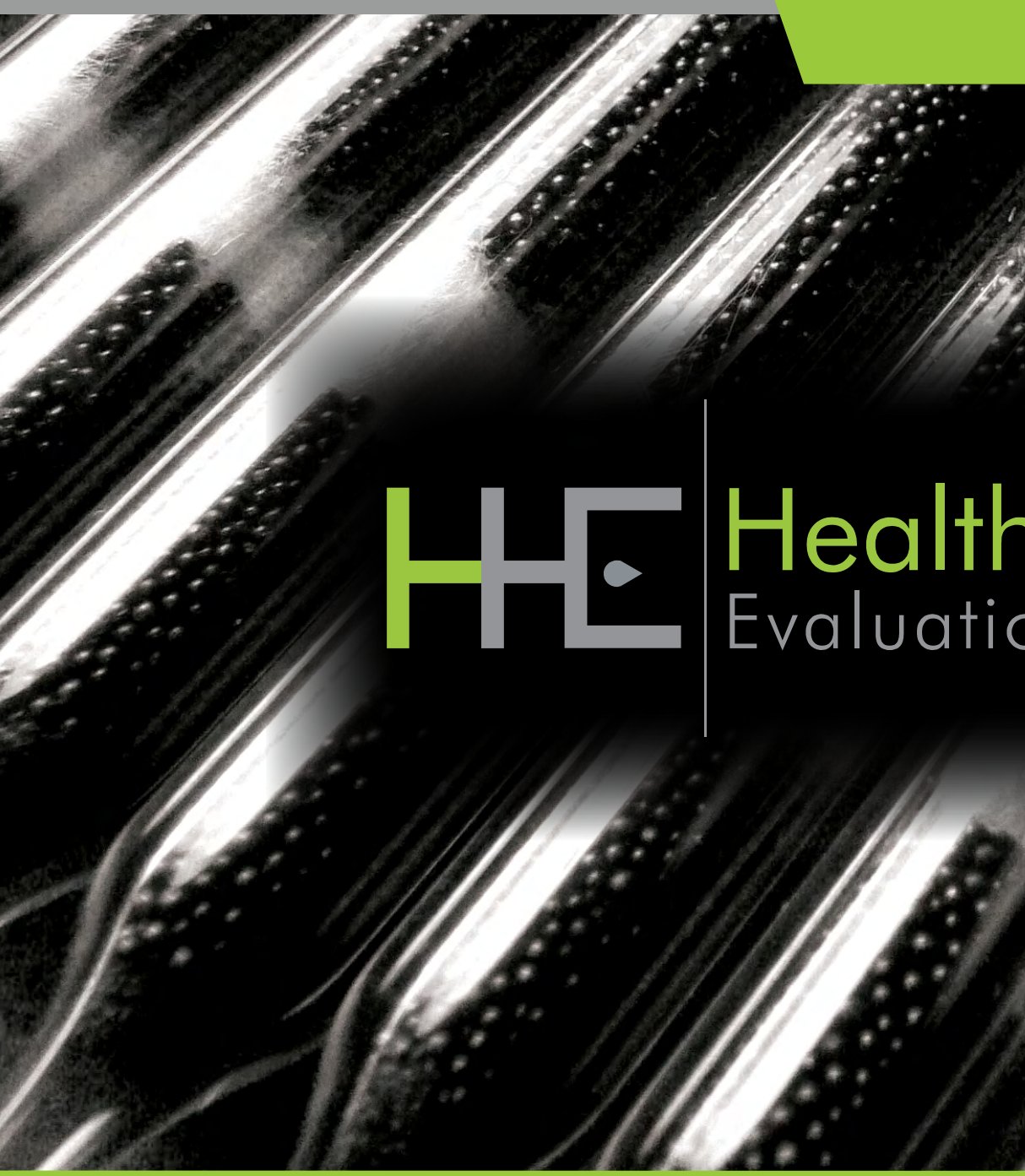

HHE Report No. 2014-0215-3250

March 2016

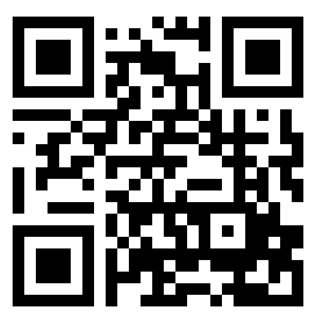

U.S. Department of Health and Human Services Centers for Disease Control and Prevention

National Institute for Occupational Safety and Health

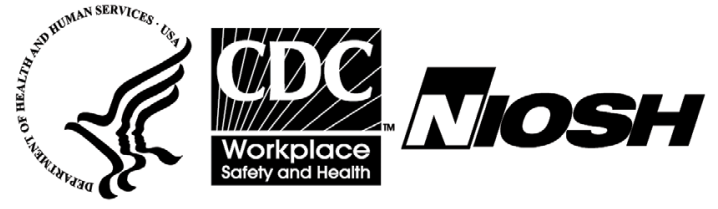




\section{Contents}

Highlights.

Abbreviations ................................... iii

Introduction ............................................ 1

Methods ............................................ 2

Results ................................................. 3

Discussion ....................................... 16

Conclusions ..................................... 18

Recommendations.......................... 18

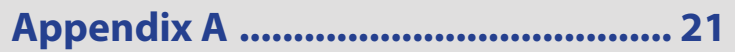

Appendix B ...................................... 24

References......................................... 27

Acknowledgements.......................... 31

The employer is required to post a copy of this report for 30 days at or near the workplace(s) of affected employees. The employer must take steps to ensure that the posted report is not altered, defaced, or covered by other material.

The cover photo is a close-up image of sorbent tubes, which are used by the HHE Program to measure airborne exposures. This photo is an artistic representation that may not be related to this Health Hazard Evaluation. Photo by NIOSH. 


\section{Highlights of this Evaluation}

The Texas Department of State Health Services asked the Health Hazard Evaluation Program for help. They asked us to evaluate silica exposure in a manufacturing plant. The plant makes natural and engineered stone countertops.

\section{What We Did}

- We measured the amount of crystalline silica in the air.

- We looked at the ventilation systems to see if they were working properly.

- We observed work activities, production processes, and personal protective equipment use.

- We interviewed employees about their work and health.

- We reviewed results of employees' previous lung function (spirometry) testing.

\section{What We Found}

- Employees using grinders with diamond cup wheels had the highest exposures to crystalline silica. Their exposures were above Occupational Safety and Health Administration limits.

- Employees working in material handling and lamination were exposed to crystalline silica levels below Occupational Safety and Health Administration limits. Their exposures, however, were above other recommended limits.

- We saw some employees incorrectly using respirators, safety glasses, and ear plugs.

- We found several electrical safety hazards. These hazards included damaged electrical

Although the company used wet methods to control dust, we found overexposures to respirable crystalline silica. Exposures were highest for employees using pneumatic wet grinders with diamond cup wheels. We recommended the company use engineering controls to decrease exposures. We also recommended establishing a medical surveillance program for employees exposed to crystalline silica. systems or cords, improper use of electrical cords, and electrical cords lying in water on the production floor.

- The company did not have an employee medical surveillance program for silica.

- We had concerns about the quality of the company's spirometry tests. Because of the problems, we could not interpret the results.

- Employees reported shortness of breath, chest pain, and loss of appetite.

- No employees reported a diagnosis of silicosis.

\section{What the Employer Can Do}

- Use local exhaust ventilation for cutting, grinding, and polishing tasks. Do this in addition to the wet methods already in use. Use a dust collector and enclosure that 
captures silica when using the pneumatic grinders with diamond cup wheels.

- Maintain the ventilation systems to ensure that they work properly, filters are changed regularly, and ductwork is not damaged or broken.

- Do a thorough electrical safety evaluation. Replace damaged electric cords and repair damaged electrical systems.

- Ensure that the spirometry provider improves the quality of spirometry testing.

- Develop a medical surveillance program for employees exposed to silica.

- Review employee training on the proper use of personal protective equipment.

\section{What Employees Can Do}

- Report work-related health concerns to the environmental health and safety manager. Also report concerns to your primary care physician.

- Wear personal protective equipment properly and consistently.

- Report safety violations or defective ventilation equipment immediately. Do not use frayed or damaged electrical equipment.

- Take part in a company silica medical surveillance program. 


\section{Abbreviations}

$\mu \mathrm{g} / \mathrm{m}^{3} \quad$ Micrograms per cubic meter

$\mu \mathrm{g} / \mathrm{sample} \quad$ Micrograms per sample

ACGIH ${ }^{\circledR} \quad$ American Conference of Governmental Industrial Hygienists

CFR Code of Federal Regulations

CNC Computer numerical control

HVAC Heating, ventilation, and air-conditioning

ND Nondetectable

NIOSH National Institute for Occupational Safety and Health

OEL Occupational exposure limit

OSHA Occupational Safety and Health Administration

PEL Permissible exposure limit

PPE Personal protective equipment

REL Recommended exposure limit

RPM Revolutions per minute

TLV® Threshold limit value

TWA Time-weighted average

TxDSHS Texas Department of State Health Services

WEEL $^{\text {TM }} \quad$ Workplace environmental exposure level 
This page left intentionally blank 


\section{Introduction}

In May 2014, the Texas Department of State Health Services (TxDSHS) was notified of a worker with silicosis. He had been employed for approximately 10 years at an engineered and natural stone countertop manufacturer as a polisher, laminator, and fabricator. To our knowledge, this was the first reported case in North America of silicosis from occupational exposure to quartz surfacing materials [CDC 2015]. It is well known that elevated crystalline silica exposures are associated with stone work, specifically work with granite [NIOSH 2002]. Granite has been reported to contain between $2 \%$ and $60 \%$ quartz, a type of crystalline silica, by volume [Phillips et al. 2013]. In contrast, engineered stone can contain a higher percentage of quartz; it can potentially contain over $90 \%$ crystalline silica [OSHA 2015a]. Silicosis is an irreversible but preventable fibrotic lung disease caused by the deposition of fine crystalline silica particles in the lungs. At least 1.7 million U.S. workers are exposed to respirable crystalline silica in a variety of industries and occupations including construction, sandblasting, and mining [NIOSH 2015].

The TxDSHS requested assistance from the National Institute for Occupational Safety and Health (NIOSH) Health Hazard Evaluation Program. They asked us to evaluate employees' exposures to airborne crystalline silica at the facility where the person with silicosis worked. We visited the facility in April 2015. During our visit we met with employer and employee representatives, measured employees' exposures to crystalline silica, and interviewed employees about their work and health.

\section{Background}

The company began operations at the current location in 2004. The employer estimated that the facility was approximately 46,000 square feet, including a production shop floor and office space. At the time of our visit, the company had 59 employees at the location. Of these, 38 employees were classified as production employees and actively worked with either natural or engineered stone. The company operated one 8-10 hour work shift per day, Monday through Friday. Most production employees worked between 6:30 a.m. and 4:30 p.m. However, the material handling employees often worked at night to prepare stone for the next day. Employees sometimes worked overtime, depending on production demands. The facility processed 100-160 pieces of stone per day, on average. The company estimated that approximately half of the materials they worked with were engineered stones and half were natural stone products, primarily granite.

The countertop production process began on the west side of the facility. Here, employees cut large slabs of engineered or natural stone into smaller pieces using bridge saws and water jet cutters. The bridge saws were equipped with a water spray to suppress dust during cutting operations. Material handlers brought the large pieces of stone to the machines via forklift. The type of machine used depended upon the type of cut required. Bridge saws made straight cuts, and water jet cutters made both straight and radial cuts. The cut stone then went to computer numerical control (CNC) machines for edging and profiling. Other large machines, such as the Comandulli machines, automatically polished the edges of the stone. All of these machines were equipped with a water spray to suppress dust during their operation. The 
process ended in the final polishing and quality control area. Employees here used hand tools equipped with a water spray to manually polish and grind the edges. Some employees used pneumatic wet polishers with resin bonded polishing discs operating at 4,500 revolutions per minute (RPM). Other employees used pneumatic wet grinders with diamond cup wheels operating at 7,000 RPM. Other employees did final quality control checks. Finished countertops were loaded onto carts and stored at the eastern side of the facility. Installation contractors waited at the east end of the facility to pick up finished countertops.

Other production jobs at the facility included lamination, in which employees wet cut thin strips of stone with a circular saw. These thin strips of stone were then glued to larger countertop pieces to form countertop edges. Some employees worked on the vanity line of countertops. Their primary job was to glue a sink into a countertop and then place it in a box for shipping.

\section{Methods}

Our primary objectives were to evaluate employees' exposures to respirable crystalline silica and possible health effects. Our work involved (1) air sampling for respirable crystalline silica, (2) evaluating the ventilation systems, (3) observing work practices, (4) reviewing company safety and health records, (5) reviewing spirometry results from the company's provider, and (6) holding confidential medical interviews with employees.

\section{Air Sampling for Respirable Crystalline Silica}

We collected full-shift personal air samples for respirable crystalline silica for 19 employees on April 7, 2015, and for 17 employees on April 8, 2015. Additionally, we collected shortduration task-based personal air samples for respirable crystalline silica on employees polishing stone and on employees using the grinders. We collected 11 task-based air samples on April 7, 2015, and 17 task-based air samples on April 8, 2015. All of the task-based samples were collected for a minimum of 24 minutes. For each task-based air sample, the corresponding worker's activity during sampling was noted along with the type of stone they worked with. We collected two representative bulk dust samples in the stone grinding and polishing area.

We collected the full-shift personal air samples using an aluminum SKC cyclone at a flow rate of 2.5 liters per minute. We collected the task-based personal air samples using a BGI model GK2.69 cyclone at a flow rate of 4.2 liters per minute. The air samples were collected and analyzed for respirable particulates according to NIOSH Method 0600 [NIOSH 2016]. The limit of detection was 50 micrograms per sample ( $\mu \mathrm{g} / \mathrm{sample})$. The limit of quantitation was $160 \mu \mathrm{g} /$ sample. The air samples and bulk samples were also analyzed for three forms of respirable crystalline silica (quartz, cristobalite, and tridymite) using x-ray diffraction according to NIOSH Method 7500 [NIOSH 2016]. The limits of detection were as follows: quartz, $5 \mu \mathrm{g} / \mathrm{sample}$; cristobalite, $5 \mu \mathrm{g} / \mathrm{sample}$; and tridymite, $10 \mu \mathrm{g} / \mathrm{sample}$. The limits of quantitation were as follows: quartz, $17 \mu \mathrm{g} / \mathrm{sample}$; cristobalite, $17 \mu \mathrm{g} / \mathrm{sample}$; and tridymite, $33 \mu \mathrm{g} / \mathrm{sample}$. 


\section{Ventilation System Evaluation}

We visually inspected the air-handling unit on a mezzanine inside the production floor and exhaust fans throughout the facility. We also inspected the accessible ductwork for damage. In addition, using thin paper strips, we evaluated pressurization of the production floor with respect to the adjacent office area.

\section{Review of Company Safety and Health Records}

We reviewed two industrial hygiene reports the company provided. The reports included respirable crystalline silica sampling results collected by an industrial hygiene consultant in April and May 2014. We also reviewed the company's written respiratory protection program.

We reviewed the Occupational Safety and Health Administration (OSHA) Form 300 Log of Work-Related Injuries and Illnesses for the years 2009-2014. As specified by OSHA, work-related injuries and illnesses are categorized into six groups: injuries, skin disorders, respiratory conditions, poisoning, hearing loss, and other [OSHA 2014]. Although recommended by OSHA and NIOSH for silica exposed employees, the company had no medical surveillance program [OSHA 2015a]. We noted that the program for respirator clearance involved spirometry, but not the medical testing and follow-up recommended for surveillance purposes.

\section{Review of Spirometry Test Results}

The company provided spirometry for respirator clearance for its employees. Spirometry tests measure how much (volume) and how fast (flow) a person can move air into and out of your lungs. During our site visit, we requested all spirometry reports for current and former employees. We received copies of spirometry results for testing completed on October 6-7, 2014. According to the spirometry provider, this was the first time that they conducted testing on employees at this facility.

\section{Confidential Medical Interviews}

We invited all 58 employees working in the production and office areas on the dates of our visit to participate in confidential medical interviews. These interviews were conducted in English or Spanish with assistance from public health interpreters. We discussed workplace exposure and work history, medical history, use of personal protective equipment (PPE) at work, and work practices.

\section{Results}

\section{Air Sampling for Respirable Crystalline Silica}

\section{Full-shift Personal Air Sample Results}

Employees used wet methods throughout the facility. Stone cutting and polishing hand tools or saws were equipped with a water spray to help control dust generated by the tool (Figure 
1). The water lines connected to the hand tools were equipped with a control knob that allowed the user to adjust the amount of water flowing to the tool. Some employees used higher water flow rates than others. We saw no dry cutting in the facility.

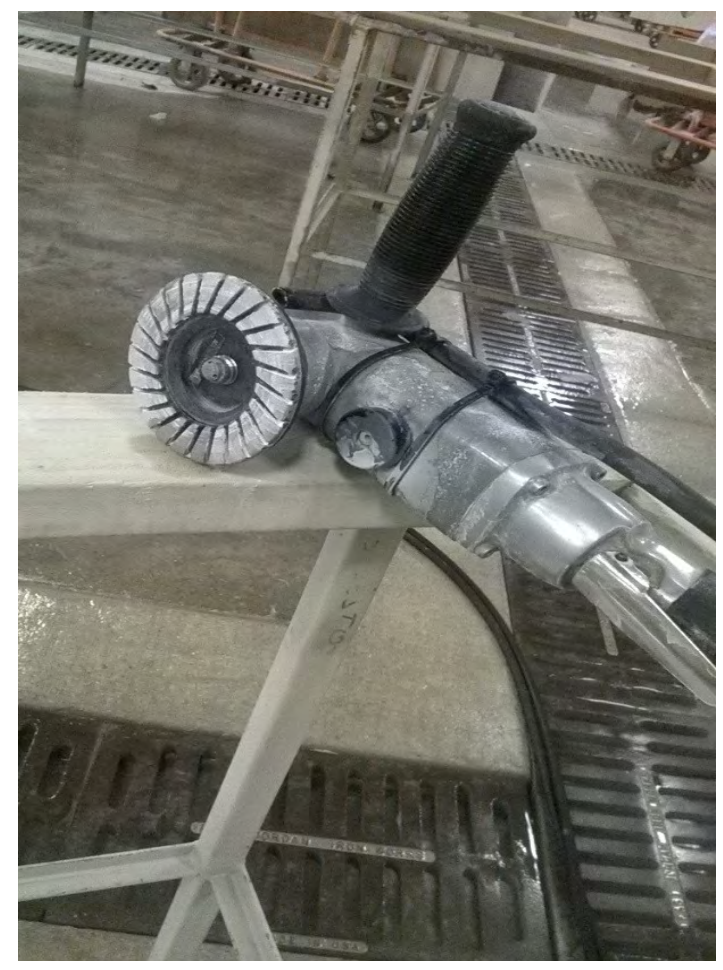

Figure 1. Photo of a pneumatic wet grinder equipped with a diamond cup wheel and a water spray used in the polishing area. Photo by NIOSH.

Employees and management reported that they typically work with both natural and engineered stone over the course of a normal day. Throughout the work shifts we observed, each employee worked with engineered and natural stones. The time spent working with each type of stone varied on the basis of customer orders and production demands. For the full-shift air samples, we were not able to track and document the time spent working with each type of stone. However, for the short-term, task-based samples, we documented whether employees worked with granite, engineered quartz, or both during the sample period.

Table A1 in Appendix A shows detailed full-shift time-weighted average (TWA) personal air sampling results. The bolded values in these tables show where silica exposures were at or above an occupational exposure limit (OEL). The OSHA permissible exposure limit (PEL) varies based on the percent quartz in each respirable dust sample, as discussed in Appendix B. The NIOSH and American Conference of Governmental Industrial Hygienists (ACGIH®) OELs for respirable crystalline silica do not vary on the basis of the percent quartz. When employees worked longer than an 8-hour work shift, we adjusted the ACGIH threshold limit value (TLV®) according to procedures recommended by Brief and Scala [1975]. The NIOSH limit is not adjusted for extended work shifts and represents exposures up to a 10-hour workday during a 40-hour workweek. 
Over both days of sampling, the percentage of quartz in the respirable dust of the full-shift air samples ranged from nondetectable (ND) to $52 \%$ (Table A1). We collected two bulk dust samples from the areas near the work benches in the manual polishing area. One contained $48 \%$ quartz and one $70 \%$. No cristobalite or tridymite were detected in any of the bulk or air samples.

Table 1. Number of respirable dust and crystalline silica samples at or above any OEL over two days of sampling

\begin{tabular}{lcc}
\hline Job title & $\begin{array}{c}\text { Number of } \\
\text { samples collected }\end{array}$ & $\begin{array}{c}\text { Number of samples } \\
\text { above any OEL }\end{array}$ \\
\hline Office area employee & 2 & 0 \\
Material handler & 3 & 1 \\
Quality control/finishing & 1 & 0 \\
Vanity & 2 & 0 \\
CNC operator & 4 & 0 \\
Laminator & 2 & 1 \\
Bridge saw & 3 & 0 \\
Water jet cutter & 3 & 0 \\
Comandulli Omega operator & 3 & 0 \\
Comandulli Synthesis operator & 2 & 0 \\
Polisher - resin bonded disc & 5 & 0 \\
Grinder - diamond cup wheel & 4 & 4 \\
Computer-aided design department & 1 & 0 \\
Maintenance & 1 & $0^{*}$ \\
\hline
\end{tabular}

${ }^{*}$ The air sample for the maintenance employee contained excessive visible debris on the air sampling filter. The employee had limited exposure to airborne silica during his work activities. The sampling result is not likely representative of the employee's actual exposure.

Table 1 presents summary results showing the number of crystalline silica or respirable dust samples at or above any OEL, over both days of sampling. Overall, the full-shift TWA respirable dust exposures ranged from ND to 380 micrograms per cubic meter $\left(\mu \mathrm{g} / \mathrm{m}^{3}\right)$, while the respirable crystalline silica exposures ranged from ND to $140 \mu \mathrm{g} / \mathrm{m}^{3}$. For both sampling days, the full-shift exposures of the employees using the pneumatic wet grinders with diamond cup wheels during the final polishing stage of production were all at or above the OSHA PEL, the NIOSH recommended exposure limit (REL), and the ACGIH TLV for crystalline silica. In contrast, none of the other production employees we sampled had exposures at or above the OSHA PEL for respirable dust containing crystalline silica. This included the pneumatic polishers with a resin bonded disc. 
The polishers and grinders used similar-looking hand tools, with the major differences being the type of disc that was used and the speed at which they were run. The polishers used resin bonded discs that ran at about 4,500 RPM, while the grinders used diamond cup wheels that ran at about 7,000 RPM. Figure 2 depicts a worker using one of the hand polishing tools.

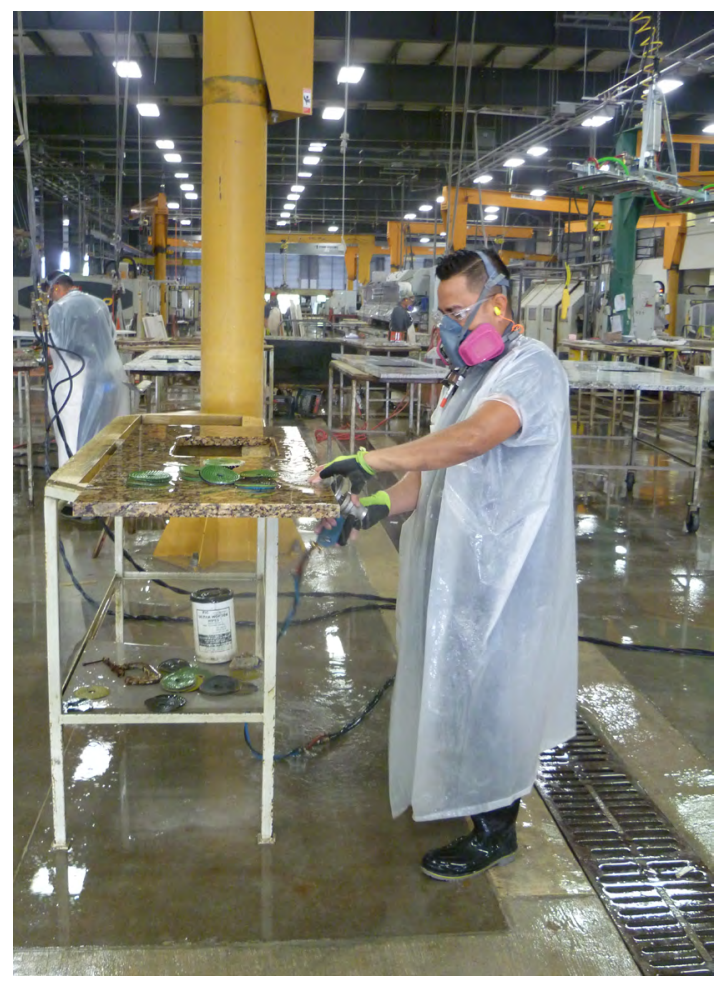

Figure 2. Employee using a hand polishing tool outfitted with a water spray. Photo by NIOSH.

Aside from the employee using the hand grinders equipped with diamond cup wheels, no other employees had an exposure to respirable dust containing crystalline silica above the OSHA PEL or to crystalline silica above the NIOSH REL. However, other employees on the production floor had exposures to crystalline silica above the ACGIH TLV. On the first day of sampling, the laminator's exposure was above the ACGIH limit of $25 \mu \mathrm{g} / \mathrm{m}^{3}$. Laminators' exposures to silica likely occur during their use of saws to cut small strips of stone or during their use of hand-held grinding and polishing tools (Figure 3). On the second day of sampling, the material handler was exposed to a crystalline silica concentration above the adjusted ACGIH limit of $13 \mu \mathrm{g} / \mathrm{m}^{3}$ for a 12-hour shift. During the second day of sampling, a CNC operator, a Comandulli Omega operator, and a laminator all had exposures close to, but slightly below, the adjusted ACGIH TLVs. None of the other employees monitored were exposed above any of the OELs for silica. Employees working in the adjacent office areas did not have detectable exposure to respirable dust containing crystalline silica or respirable crystalline silica. 


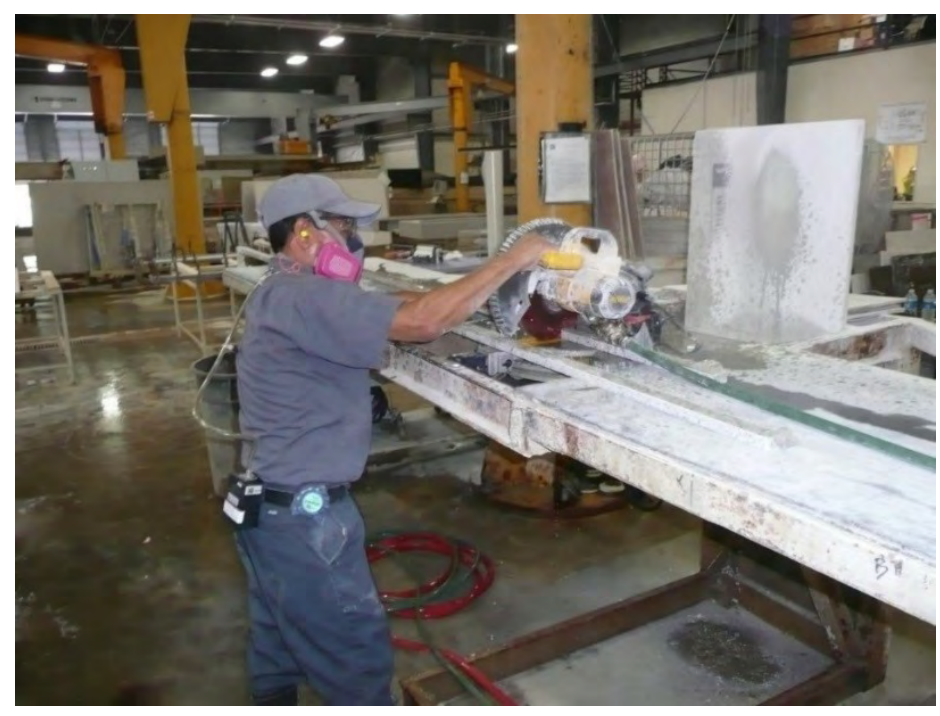

Figure 3. Photo of a lamination employee making a cut with a miter saw. Photo by NIOSH.

\section{Task-based Air Sampling Results}

Table A2 in Appendix A reports the TWA respirable dust concentrations and the TWA respirable crystalline silica concentrations for short-term, task-based breathing zone air samples. There are no short-term OELs for silica. These samples provided information about the employee's exposure to crystalline silica while performing specific tasks.

Overall, respirable dust exposures during the short-term polishing and grinding tasks ranged from ND to $430 \mu \mathrm{g} / \mathrm{m}^{3}$ for the polishers, and from 200 to $550 \mu \mathrm{g} / \mathrm{m}^{3}$ for the two grinders. Respirable crystalline silica exposures during the short-term polishing and grinding tasks ranged from ND to $140 \mu \mathrm{g} / \mathrm{m}^{3}$ for the polishers, and from 50 to $140 \mu \mathrm{g} / \mathrm{m}^{3}$ for the two grinders.

\section{Ventilation System Evaluation}

No mechanical heating or cooling was provided to the main production floor by a heating, ventilation, and air-conditioning (HVAC) system. However, general exhaust ventilation of the production floor was provided by large exhaust fans in the roof of the building and large bay doors on the east end of the building. These doors were open at the time of our visit. The employer stated that the doors were typically open, except during the winter. None of the work processes used local exhaust ventilation.

Two rooftop-mounted Trane ${ }^{\circledR}$ air-handling units provided ducted supply air to the office spaces adjacent to the production floor. A Payne ${ }^{\circledR}$ air-handling unit on a mezzanine inside the production floor and outside the conference room also served the office space. We observed standing water and extensive rust and biological growth in the condensate drain pan for the Payne ${ }^{\circledR}$ air-handling unit (Figure 4). We also observed that the unit was missing its air filter 
and that some of the flexible duct attached to the unit was torn (Figure 5). This unit was in the production area, so openings in the flexible duct could allow crystalline silica or other dusts from the production area to enter the office space. Employer representatives stated that an HVAC contractor serviced these units, and that they were unsure how often the filters were changed.

Pressurization checks between the production floor and the adjoining office space indicated that the production floor was negatively pressurized with respect to the adjacent office area. This will help limit the amount of airborne crystalline silica or other dust entering the office space when employees open the door to the production floor.

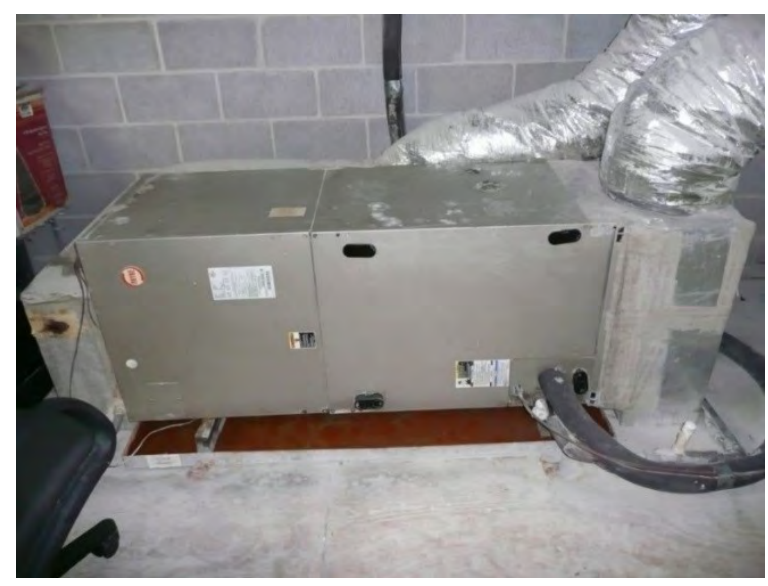

Figure 4. Discolored standing water in the drain pan of the air-handling unit on the mezzanine. Photo by $\mathrm{NIOSH}$.

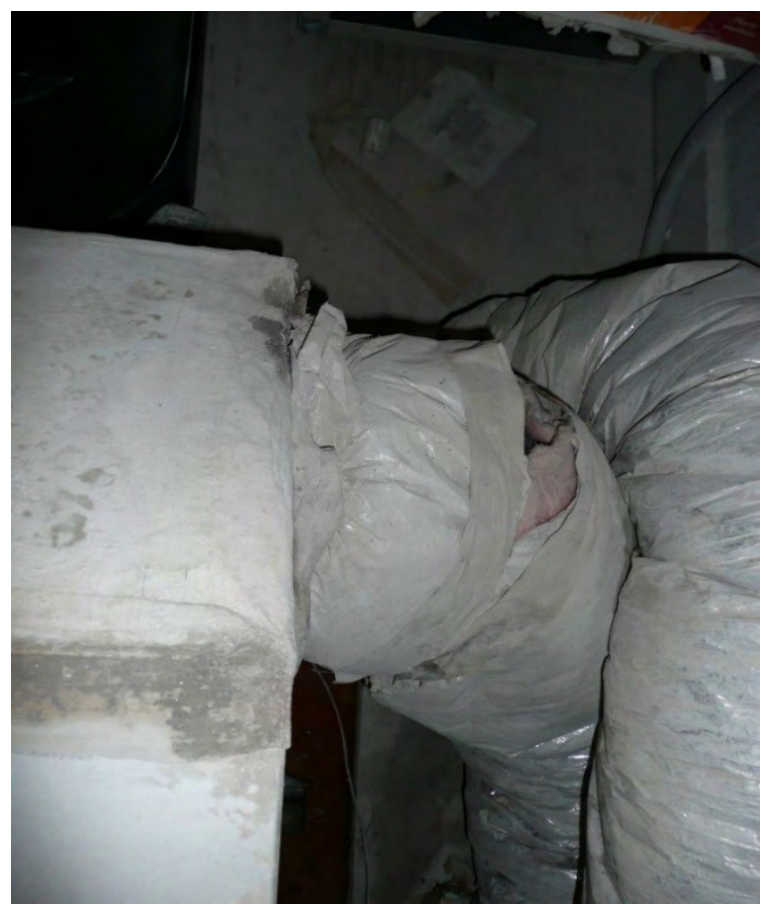

Figure 5. Torn flexible duct attached to the air-handling unit on the mezzanine. Photo by NIOSH. 


\section{Workplace Observations and Safety Hazards}

\section{Personal Protective Equipment Use}

Employees in production areas were required to use respiratory protection, hearing protection, eye protection, rubber safety shoes, nylon knitted work gloves with latex dipped palms and fingers, and vinyl aprons. The employer provided uniforms to the employees at the beginning of each day. A contractor laundered the uniforms offsite. We observed that not all employees properly wore their safety glasses while on the production floor. We observed one employee wearing safety glasses on top of his head while using a hand polishing tool. Not all employees wore gloves while on the production floor, and some employees had cut off the tips of their gloves. We also observed an employee wearing his insert-type foam hearing protection sideways in his ear. Additionally, it appeared that some employees did not insert their hearing protection deeply enough into their ear canal.

We observed that all employees wore respirators when entering the production floor as required by the company. Production employees wore elastomeric, half-face air-purifying respirators (3M model 7502). Most production employees used P100 particulate filter cartridges (3M model 7093) with their respirator; however, laminators used combination P100 and organic vapor cartridges (3M model 60921). The respirator program administrator reported that employees changed P100 cartridges once per week and changed combination cartridges at least once per month, but could change them more often if requested. An employee reported during informal discussions that he usually changed cartridges once each week. Employees who were not primarily working on the production floor, such as managers or office staff, donned N95 filtering facepiece respirators (3M model 8200 or ULine model S-9632) prior to entering the production floor. In most instances, respirators were worn properly. However, we observed the following instances of improper respirator use:

- Some employees wore the straps of N95 filtering facepiece respirators incorrectly, such as wearing both straps around the base of the neck, using only one of the two straps, or cutting off one of the straps. Respirators only fit tightly and seal properly if both straps are used correctly.

- Some employees or managers had facial hair that could interfere with the seal of the respirator to the face.

- We observed that employees or managers sometimes pulled the respirator away from their face when speaking with other employees. This practice allows air contaminants to be breathed in.

\section{Safety Hazards}

The handle on the maintenance office door was broken, and the door would not close. This office was connected to the production floor, and the open door could allow airborne silica to enter the maintenance office (Figure 6). The maintenance supervisor used the office and did not wear a respirator when inside. 


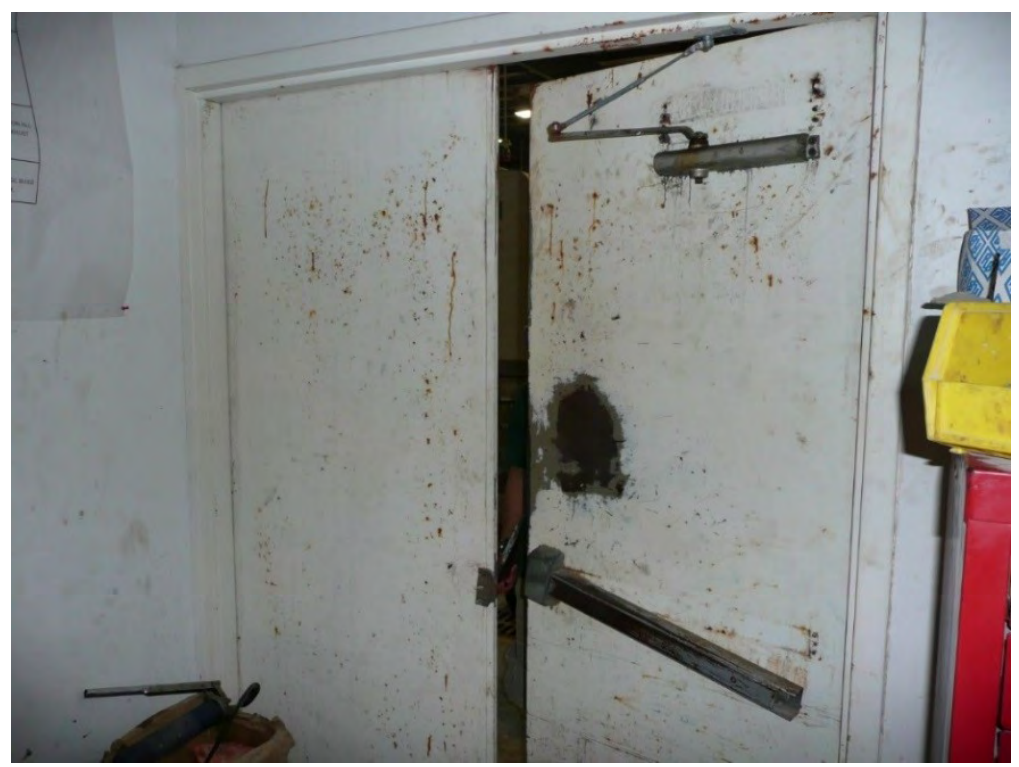

Figure 6. View of broken door from inside of the maintenance room, looking out to the production floor. Photo by NIOSH.

We observed that the pneumatic stone slab lifter attached to a half-ton overhead crane remained in a suspended position about 6 to 8 feet above the floor during times it was not in use. Employees sometimes walked under the suspended slab lifting device (Figure 7).

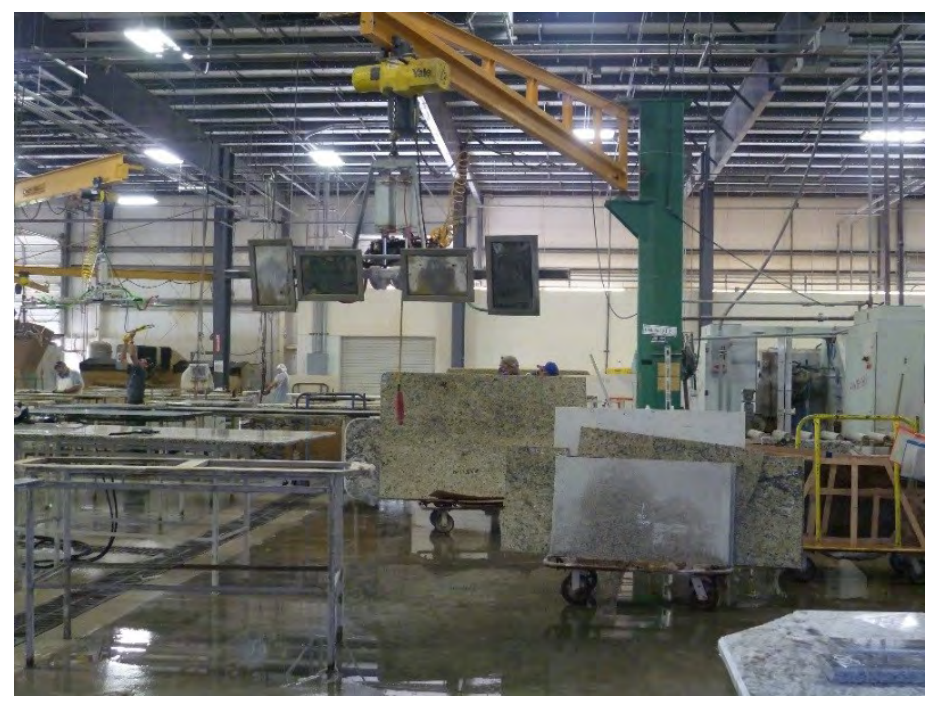

Figure 7. Slab lifter attached to overhead crane. Photo by NIOSH. 
We observed an employee standing on the side of a forklift, which is an unsafe work practice, while the forklift operator lifted and removed large stone slabs from a semi-trailer. The employee was helping instruct the operator on positioning the forks and backing the slabs out of the trailer without damaging other slabs in the trailer.

We noted several electrical safety hazards during our site visit, specifically:

- Electrical cords were lying in water (Figure 8).

- Electrical cords had damaged or torn insulation jackets. Some had been repaired using electrical tape (Figure 9), and others had exposed inner wires (Figure 10).

- Three long lengths of extension cords were daisy-chained (i.e., connected in series) from the production building to the outside stone slab storage area behind the building. We also observed extension cords daisy-chained to power strips.

- An electrical junction box attached to a Comandulli machine was severely damaged from oxidation and rust. The electrical power supply fittings were dangling loose from the junction box, exposing internal electrical wiring junction box connection points (Figure 11).

- A forklift operator drove over an extension cord that had been stretched across the inclined loading dock in the back of the building. The cord was plugged into an electrical outlet in the building and was connected to a series of daisy-chained extension cords that were stretched across a field to a reciprocating saw being used to cut wooden support frames in the back of a semi-trailer.

- The expanded metal housing on the end of a Comandulli machine motor was corroded and partially missing.

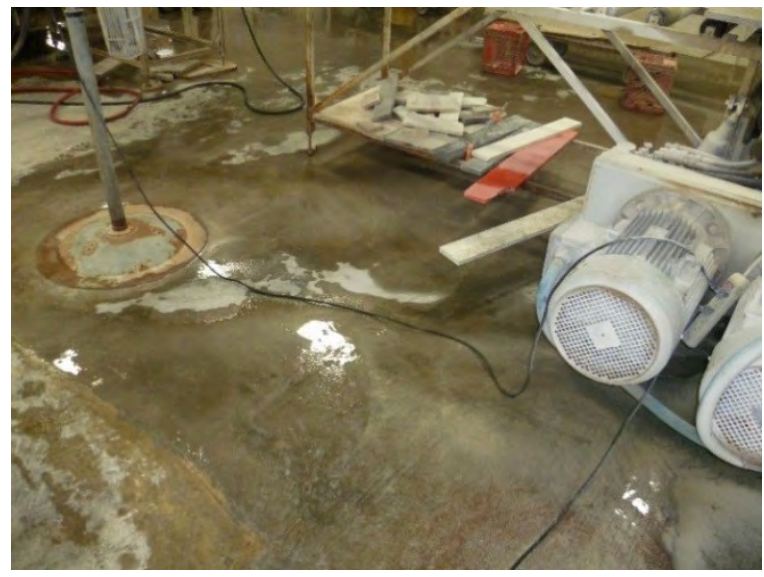

Figure 8. Electrical cords in water. Photo by $\mathrm{NIOSH}$. 


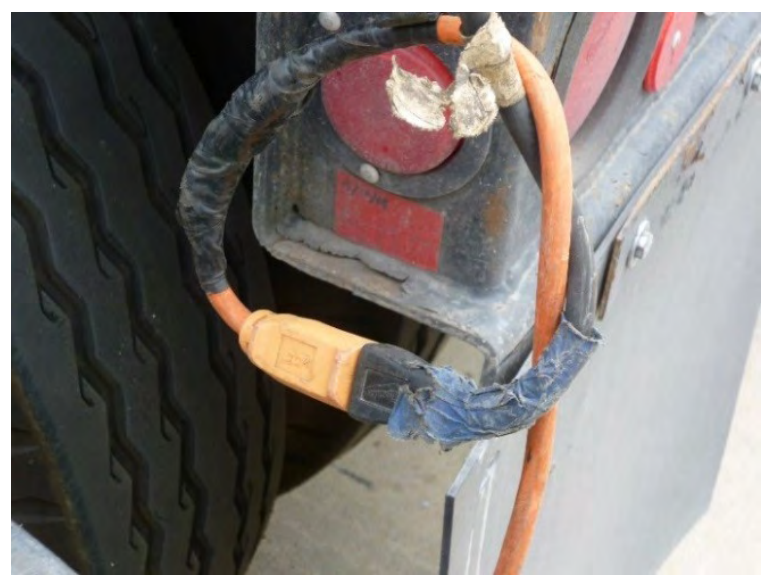

Figure 9. Electrical cords with damaged or torn insulation jackets. Photo by $\mathrm{NIOSH}$.

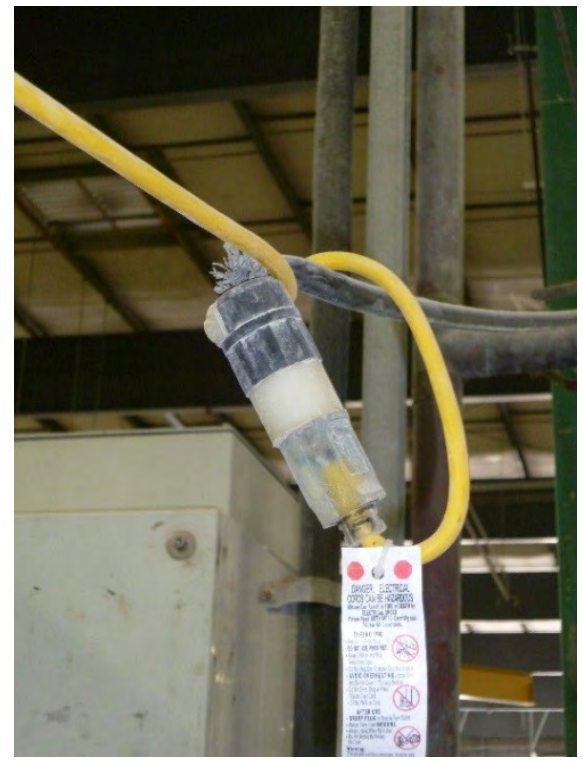

Figure 10. Extension cord with damaged insulation jacket near the plug. Photo by $\mathrm{NIOSH}$.

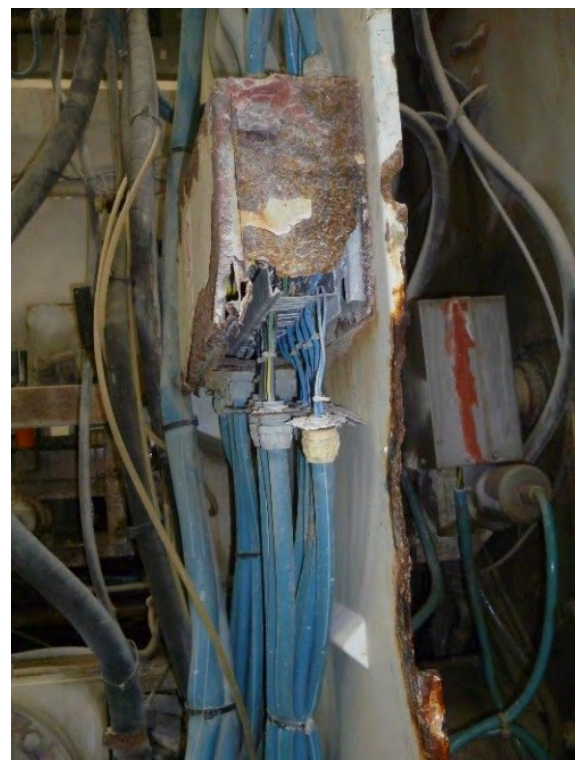

Figure 11. Severely damaged electrical junction box at Comandulli machine. Photo by NIOSH. 


\section{Review of Company Safety and Health Records}

\section{Review of Industrial Hygiene Reports}

The company provided us with two industrial hygiene reports. These reports detailed the results of personal air sampling for respirable crystalline silica. In April 2014, an insurance company representative did personal air sampling on four employees. None of the employees' 8-hour TWA exposures were greater than 50\% of the OSHA PEL, and no samples were above the NIOSH REL of $50 \mu \mathrm{g} / \mathrm{m}^{3}$. However, three of the four personal samples were above the ACGIH TLV of $25 \mu \mathrm{g} / \mathrm{m}^{3}$. The employees overexposed to the TLV included one working at the bridge saw, one using a Comandulli machine, and one doing countertop manual fabrication. The type of tool used by the employee performing the manual fabrication tasks was not reported. The employee who was not overexposed was reported to be doing maintenance tasks and working in the "filteration" [sic] room. While we did not observe any overexposures in our sampling for the bridge saw operators, one of the Comandulli operators had crystalline silica exposures just below the TLV. The results for the employee performing manual fabrication are not directly comparable to our results, as we do not know what type of tool the employee was using.

In May 2014, a consultant did personal air sampling on five employees throughout the facility for varying lengths of times. The consultant also took one area air sample in the

polishing area. Four of the employees sampled were described as working in fabrication, and one was described as working in lamination. None of the employees' 8-hour TWA exposures was above the OSHA PEL; however, two of the fabrication employees' 8-hour TWA exposures were greater than $50 \%$ of the OSHA PEL. Comparisons to the ACGIH TLV and NIOSH REL were not discussed in this report. Neither of the reports commented on whether any of the sampled employees were using pneumatic grinders with the diamond cup wheel.

\section{Review of the Written Respiratory Protection Program}

The company developed a written respiratory protection program in 2014 . We noted the following during our review:

- Medical clearance to wear a respirator was evaluated using only spirometry. However, the company did not follow NIOSH and OSHA recommended medical surveillance program guidelines for silica [OSHA 2015a].

- Attachment D of the written respirator program indicated that all employees wore half mask air purifying respirators with P100 filters. However, laminators used combination cartridges, and nonproduction staff wore N95 filtering facepiece respirators.

- The information on selection of respirators for laminators did not show that laminators were exposed to airborne chemicals nor provide the identity and possible airborne concentrations of these chemicals. This information is needed to provide the basis for the selection of the chemical cartridges and for setting the change-out schedule.

- The program administrator (the general manager) was identified as providing respirator training. However, we were told an external contractor provided training. Additionally, 
the program indicated that training was assessed through a written test, but we learned that training was assessed by observing employees donning and doffing respirators.

- There was no information about specific fit test procedures. For example, the program did not state that an external contractor conducts fit testing using Bitrex (a qualitative fit test agent).

- Employees were provided with respirator cleaning wipes from Magic Safety Products Company for cleaning their elastomeric respirators, not the 3M 504 wipes as described.

\section{Summary of OSHA Form 300 Logs of Work-Related Injuries and IIInesses}

During 2009-2014, 27 entries were recorded. Most entries were injuries, which included cuts, foreign objects in the eyes, and back and forearm pain. No respiratory illnesses were reported on OSHA logs from 2009-2014.

\section{Review of Spirometry Results}

Spirometry tests are normally used to monitor changes in lung function over time and to identify abnormal declines in lung function [Miller et al. 2005]. In 2014, the company had spirometry testing done on employees at the facility. This was the first time the company had spirometry testing available to employees. However, according to the company's health provider, the spirometry conducted on employees was for the medical clearance process for respirator use and was not done for the purpose of medical surveillance.

We reviewed spirometry reports for 55 employees from October 2014 and the methods used for interpreting those reports. During our site visit, we found that three new employees hired after October 2014 did not have a spirometry test done. The spirometry tests were conducted by the company's health provider for all production and office employees. Each test result showed the flow-volume and volume-time curves and indicated the number of efforts performed and the prediction equations that were used. Overall, the best of three trials was reported on each test, and the values were compared to the predicated values generated from National Health and Nutrition Examination Survey III spirometry reference equations for adults [Hankinson et al. 1999], which is the method recommended by NIOSH. The provider used additional criteria to determine clearance for respirator use. An employee with a forced vital capacity $\geq 70 \%$ of the predicted value and a forced expiratory volume in one second $\geq 70 \%$ of the predicted value was determined to be cleared.

During our review, we identified several technical errors in the spirometry testing which affected their validity and interpretability. Almost all spirometry tests $(53 / 55,96 \%)$ had technical problems and did not meet American Thoracic Society standards [Miller et al. 2005]. The problems included evidence of poor effort, absence of a plateau, and test lengths less than 6 seconds.

\section{Confidential Medical Interviews}

All 58 invited employees participated in the interviews. Forty-seven (81\%) were male, and $11(19 \%)$ were female. The median age was 35 years (range: $25-60$ years) with most 
employees $<45$ years old ( $84 \%$ ). Most employees reported their ethnicity as Hispanic or Latino $(81 \%)$. Among those we interviewed, $21(36 \%)$ were fabricators, $22(38 \%)$ operators, and 15 $(26 \%)$ office or managerial employees. The median years worked at the facility was 3 (range: 1 week-17 years), with most employees working for the company $<10$ years $(67 \%)$. The median number of hours worked per week was 40 (range: 40-70 hours). Seventeen employees (29\%) reported working in another job where they were exposed to silica dust; the median time worked was 5.5 years (range: $<1-20$ years). Twenty-four employees $(41 \%)$ reported that they were a current or former smoker with an average pack-years of 24 . Of these, $12(50 \%)$ currently smoke with a median of 7.5 cigarettes smoked per day (range: 4-20).

Regarding exposures, 44 (76\%) employees reported performing at least one task at work that could expose them to silica dust. Among these employees, one office employee reported sometimes working in the production area. Table 2 shows the tasks reported by employees.

Table 2. Description of work tasks reported by interviewed employees

\begin{tabular}{lc}
\hline Task & $\begin{array}{c}\text { Number of employees (\%) } \\
\mathrm{n}=44\end{array}$ \\
\hline Wet cutting & $26(45)$ \\
Polishing & $20(34)$ \\
Sanding & $15(26)$ \\
Grinding & $12(21)$ \\
Chipping & $10(17)$ \\
Drilling & $9(16)$ \\
Crushing & $4(7)$ \\
Dry cutting & $1(2)$ \\
\hline
\end{tabular}

Thirty-five employees (80\%) stated that they clean or sweep up dust after performing any of the tasks listed in Table 2. We also asked these 35 employees about the use of wet methods to clean up dust. Twenty-five (71\%) stated that they always use wet methods, 4 (11\%) sometimes, and $6(17 \%)$ never. Of the six who reported never using wet methods, five worked in the production area.

Employees were asked about the use of PPE on the job. All 57 interviewed employees who reported going into the production area stated that they always wear a respirator while in the production area. Twelve employees $(21 \%)$ reported not having received training on the use of respirators in the last year. Among these were four operators, four fabricators, and four office employees. Thirteen employees $(22 \%)$ reported not having received training on the hazards of crystalline silica related to their work at the facility. These employees included five operators, four fabricators, and four office employees.

Seven (12\%) employees reported symptoms that could be related to silica exposure, excluding symptoms related to colds or respiratory infections, in the previous 4 weeks. 
Symptoms reported included shortness of breath $(n=2)$, chest pain $(n=2)$, and loss of appetite $(n=3)$. No one reported cough, discoloration of skin, or unexplained weight loss which are symptoms that could be related to exposure to silica. Employees stated that they believed their symptoms were related to activities like smoking, air pollution, lack of exercise, and their weight. Only two employees reported that they had sought medical care for their symptoms. Among those reporting symptoms, five were office and two were production area employees. Both production area employees had worked for the company for less than 2 years. None of the 58 interviewed employees reported that they were ever diagnosed with silicosis, asthma, tuberculosis, other lung diseases, or kidney disease. Other concerns expressed by employees were back pain, dust, and poor ventilation, especially in the winter.

\section{Discussion}

In 2015, OSHA and NIOSH jointly published a Hazard Alert document identifying exposure to airborne crystalline silica as a health hazard in the natural and engineered stone countertop industry [OSHA 2015a]. In this alert, OSHA recommended that employers take protective actions to keep employee exposures below the NIOSH REL. In our evaluation, we found that employees working in the production area were exposed to crystalline silica above OELs.

We observed the use of wet cutting, grinding, and polishing methods at all equipment and tasks. The company did not have local exhaust ventilation for any equipment or tasks. Wet cutting processes have been found to produce lower respirable crystalline silica concentrations than dry cutting processes in countertop fabrication shops [Simcox et al. 1999; Phillips et al. 2013; Cooper et al. 2015]. Although employees always used appropriate respirators and used a water spray on the grinders to suppress dust, during both days of fullshift sampling, employees grinding stone with the diamond cup wheels were consistently overexposed to the ACGIH TLV, the NIOSH REL, and the OSHA PEL. The task-based samples reveal that wet grinding both types of stones and wet polishing the engineered quartz stone can result in high task-based exposures to silica that could lead to overexposures. Some types of engineered quartz can have higher silica concentrations than granite. For the polishing tasks where only one type of stone was used, the concentrations during granite polishing were generally lower than the concentrations found when polishing engineered quartz. This is likely due to the difference in silica content between the granite and the engineered stone. Full-shift crystalline silica exposures are largely determined by how much time the employees spend at these grinding and polishing tasks each day, as well as the silica concentrations they are exposed to during each of their work tasks. If an employee is wet grinding stone at the mean silica concentration we observed of $96 \mu \mathrm{g} / \mathrm{m}^{3}$, then that person would be overexposed to the REL after only 5 hours.

We also found that employees in material handling and lamination jobs were exposed to respirable crystalline silica above the ACGIH TLV. We found detectable levels of respirable crystalline silica for all other production jobs, but not in the office areas.

Our findings indicate that water suppression alone was not sufficient in reducing crystalline silica concentrations below OELs. A recent study showed that a combination of water 
suppression and local exhaust ventilation are more effective than water suppression alone in reducing crystalline silica concentrations [Cooper et al. 2015]. This approach could be applied to this facility to help reduce airborne crystalline silica concentrations.

Chronic or classic silicosis is the most common form of silicosis that occurs after 15-20 years of moderate to low exposures to respirable crystalline silica [OSHA 2002]. In the early stages of the disease, symptoms associated with chronic silicosis may or may not be obvious. As the disease progresses, a person with silicosis may experience shortness of breath upon exercising and in the later stages of the disease, may experience fatigue, extreme shortness of breath, chest pain, weight loss, or respiratory failure [OSHA 2002]. Although two production employees reported symptoms that might be compatible with silicosis, they had worked at the company for less than 2 years, which is less than the time it usually takes for symptoms of chronic silicosis to develop after exposure. Furthermore, reported symptoms can also occur with many other diseases that are not work-related. Given that employees with silicosis may be asymptomatic, a medical surveillance program is needed to detect early signs of adverse effects and to prevent the development of silicosis. NIOSH also considers crystalline silica to be an occupational carcinogen and workers are also at risk for chronic obstructive pulmonary disease as well as kidney disease.

As part of its National Emphasis Program on Silica, OSHA recommends that employers provide medical exams to all employees who may be exposed to silica levels at or above onehalf the PEL [OSHA 2015a]. Medical tests recommended by NIOSH and OSHA consist of a medical exam that focuses on the respiratory system and includes work and medical history and a chest radiograph read by a board-certified radiologist or certified class "B" reader [OSHA 2002, 2015a]. We found that two employees (grinders) were exposed to levels of crystalline silica above the OSHA PEL on both days we sampled and thus meet the OSHArecommended criterion for inclusion in a medical surveillance program. Although we did not find additional employees exposed to levels of crystalline silica at or above one half of the PEL, the use of extended work shifts, high short-term exposures to silica, and variability in work tasks and silica content of the stones suggests the need for a cautious approach to risk management decisions concerning medical surveillance and use of the most protective OELs. In addition, previous studies have shown that smokers are more susceptible to the long-term effects of silica dust [Brown 2009]. Therefore, employees who currently smoke might be at increased risk of developing chronic silicosis. Medical surveillance through monitoring of spirometry results over time can identify employees with abnormal declines in lung function. This is important for all exposed employees, but especially pertinent for employees who continue to smoke and are exposed to silica dust.

This evaluation had limitations that could influence the generalizability of our findings. First, sampling occurred over 2 days in the spring of 2015, which may not be representative of other times or seasons. The number of hours an employee works can vary by season, due to changing demand for the product. Second, $95 \%$ of the spirometry tests we reviewed were invalid due to poor technique, and were not interpretable. Finally, during our site visit we interviewed only current employees; it is possible that our findings related to symptoms and the diagnosis of silicosis would have been different had we included former employees. 


\section{Conclusions}

Employees, specifically those grinding stone with the diamond cup wheels, were exposed to crystalline silica above OELs despite use of wet cutting methods. Installing and using local exhaust ventilation to capture crystalline silica particles at the source in addition to the continued use of wet methods, improving PPE practices, and enhancing medical surveillance are needed to reduce crystalline silica exposures and prevent long-term adverse health effects.

\section{Recommendations}

On the basis of our findings, we recommend the actions listed below. We encourage the company to use a labor-management health and safety committee or working group to discuss our recommendations and develop an action plan. Those involved in the work can best set priorities and assess the feasibility of our recommendations for the specific situation at the facility.

Our recommendations are based on an approach known as the hierarchy of controls (Appendix A). This approach groups actions by their likely effectiveness in reducing or removing hazards. In most cases, the preferred approach is to eliminate hazardous materials or processes and install engineering controls to reduce exposure or shield employees. Until such controls are in place, or if they are not effective or feasible, administrative measures and PPE may be needed.

\section{Engineering Controls}

Engineering controls reduce employees' exposures by removing the hazard from the process or by placing a barrier between the hazard and the employee. Engineering controls protect employees effectively without placing primary responsibility of implementation on the employee.

1. Use local exhaust ventilation and wet methods during cutting, grinding, and polishing. Studies have shown that this combined use is the most effective way to reduce airborne crystalline silica concentrations [Cooper et al. 2015].

2. Conduct tasks with potential for high crystalline silica exposure, such as grinding with diamond cup wheels, inside a negative pressure enclosure that uses a dust collection system specifically designed to capture and remove airborne silica from the working environment. The new enclosure should have a dust collector equipped with highefficiency air filtration to remove captured crystalline silica particles that are created during work tasks performed inside the enclosure.

3. Fix the door to the maintenance office to ensure that it closes properly. This will eliminate a potential pathway for silica or other dusts to enter the maintenance room.

4. Replace the damaged electrical junction box at the Comandulli machine and utilize a weather-resistant junction box or install a water-repellant shroud over the top of the box to help protect it from water splashes or drips.

5. Install fixed wiring that extends down from the ceiling to eliminate electrical cords snaking across the wet production floor. 


\section{Administrative Controls}

The term administrative controls refers to employer-dictated work practices and policies to reduce or prevent hazardous exposures. Their effectiveness depends on employer commitment and employee acceptance. Regular monitoring and reinforcement are necessary to ensure that policies and procedures are followed consistently.

1. Educate all employees on the hazards of working with crystalline silica.

2. Ensure that the spirometry provider conducts high quality spirometry testing consistent with American Thoracic Society standards [Miller et al. 2005].

3. Implement a medical surveillance program for silica that follows recommended guidelines from NIOSH and OSHA [OSHA 2015a]. They should consult with a clinician familiar with health effects of silica to develop the program. The program should include a medical examination focusing on the respiratory system and chest radiographs for workers exposed to silica [OSHA 2015b].

4. Encourage employees to report any respiratory symptoms that they suspect might be related to their work exposure to the environmental health and safety manager and their primary care physician.

5. Encourage employees who smoke to participate in smoking cessation programs. This is especially important because of the effects of combined exposure to tobacco smoke and crystalline silica on the lungs.

6. Use wet sweeping methods or a HEPA-filtered vacuum to clean up dust after working with stone. Do not dry sweep dust.

7. Contact the HVAC contractor to determine the frequency of the HVAC filter changeouts and proper system maintenance schedule for the systems throughout the facility. Follow the manufacturers' recommended schedule.

8. Inspect HVAC ductwork regularly and promptly complete repairs, if needed.

9. Inspect electric cords and electrical systems regularly. Promptly replace damaged electrical cords and repair damaged equipment.

10. Never place electrical cords across aisles subject to forklift traffic. Instruct forklift operators to never drive over electrical cords.

11. Do not connect multiple electrical cords or power strips together as it increases the risk of fire and electrocution.

12. Instruct employees using overhead cranes to lower the loads or the slab lifter to the floor if they must leave the controls. OSHA requires that crane operators remain at the controls when the load is suspended in the air [29 CFR 1910.179(n)].

13. Contact the Texas OSHA consultation program for free additional assistance in addressing electrical and other safety hazards. You can contact them by phone at 800-252-7031, by email at OSHCON@tdi.texas.gov, or through their website at http:// www.tdi.texas.gov/oshcon/. 
14. Conduct additional exposure monitoring for crystalline silica after any changes are made to the fabrication process, the control equipment, or to any work practices that may be expected to alter employees' exposures. The purpose of this is to assess the need for additional exposure control measures and to determine the appropriate level of respiratory protection, if necessary.

15. Inform the uniform laundering contractor that the uniforms may contain crystalline silica dust.

\section{Personal Protective Equipment}

Personal protective equipment is the least effective means for controlling hazardous exposures. Proper use of PPE requires a comprehensive program and a high level of employee involvement and commitment. The right PPE must be chosen for each hazard. Supporting programs such as training, change-out schedules, and medical assessment may be needed. Personal protective equipment should not be the sole method for controlling hazardous exposures. Rather, PPE should be used until effective engineering and administrative controls are in place.

1. Review the proper use of safety glasses and hearing protection with employees to ensure that they are worn properly.

2. Ensure that employees do not have beard growth that interferes with the sealing surface of respirators.

3. Retrain employees wearing N95 filtering facepiece respirators on how to properly position the respirator straps during use.

4. Instruct all employees that they should not pull a respirator away from their face to speak.

5. Review the written respiratory protection program to ensure that the information in the program is current, accurate, and provides details on the types of respirators and filters or cartridges used, air contaminant exposures, selection criteria, training program, fit testing procedures, cleaning procedures, and medical evaluation procedures. Review the program yearly and update the information, if needed. 


\section{Appendix A: Tables}

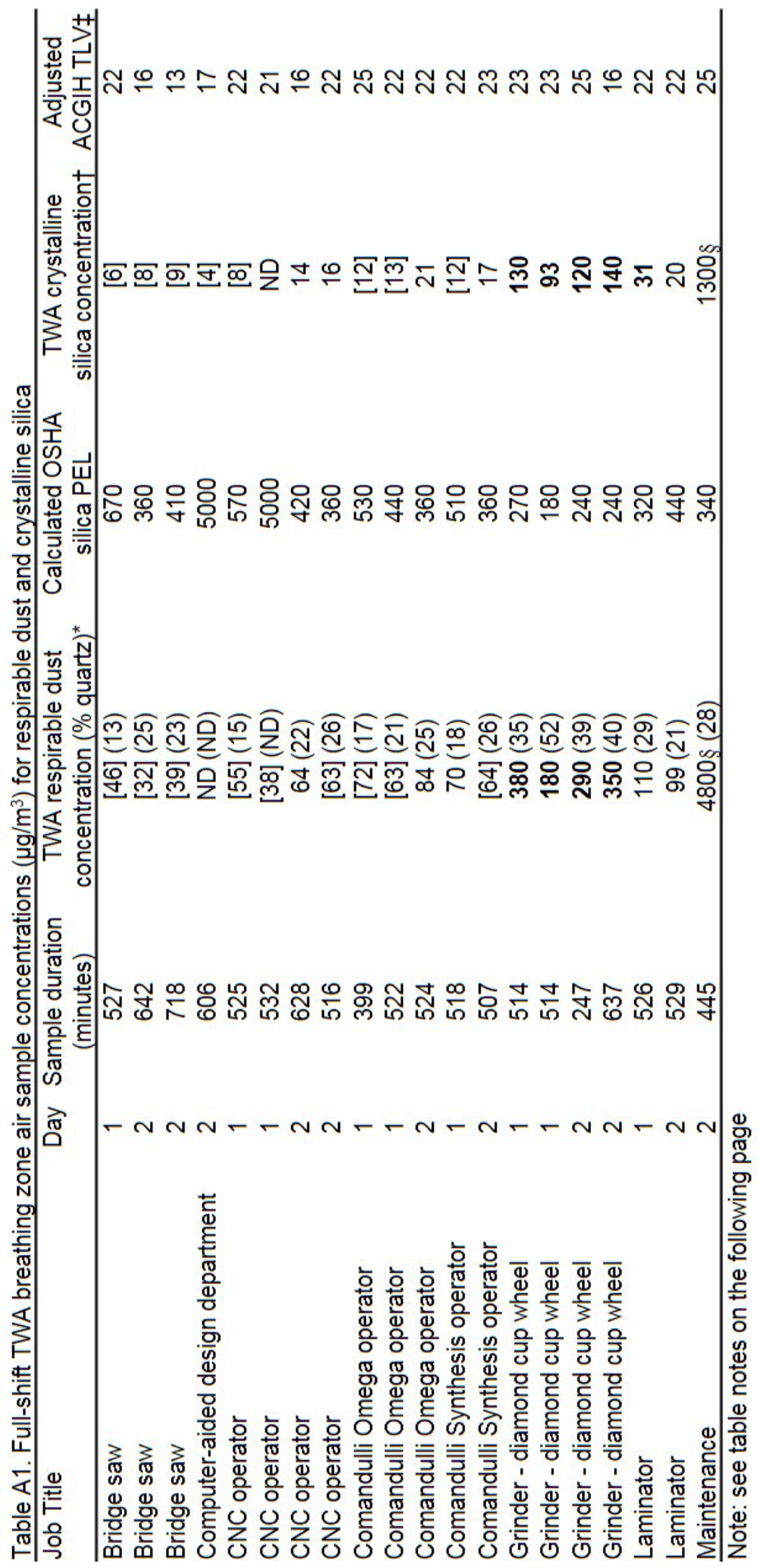




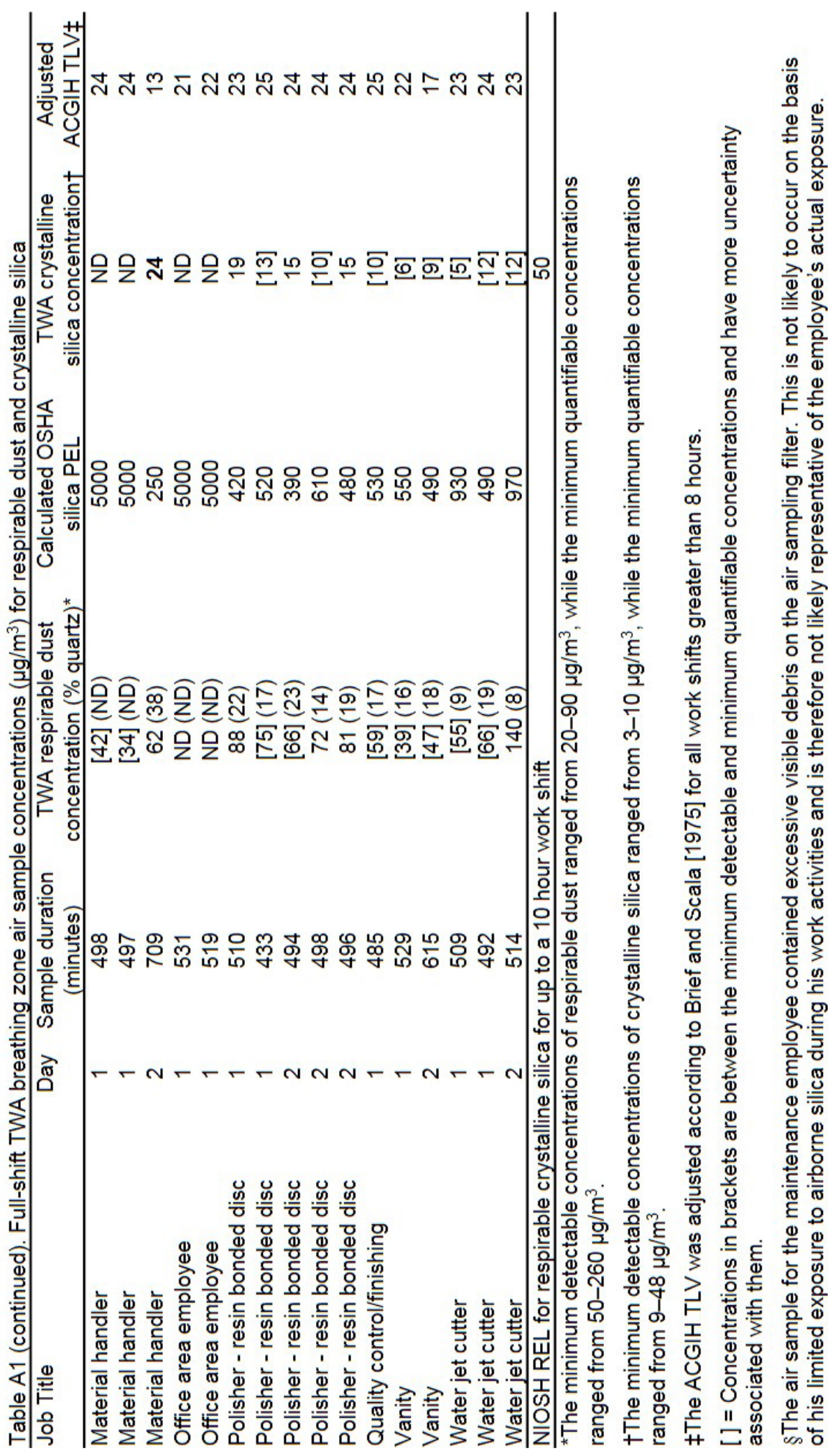


Table A2. Task-based breathing zone air sample concentrations $\left(\mu \mathrm{g} / \mathrm{m}^{3}\right)$ for respirable dust and crystalline silica

\begin{tabular}{|c|c|c|c|c|c|}
\hline Task & Day & $\begin{array}{l}\text { Sample } \\
\text { duration } \\
\text { (min) }\end{array}$ & Stone type & $\begin{array}{c}\text { TWA } \\
\text { respirable dust } \\
\text { concentration } \\
(\% \text { quartz })^{*}\end{array}$ & $\begin{array}{c}\text { TWA } \\
\text { crystalline silica } \\
\text { concentration† }\end{array}$ \\
\hline $\begin{array}{l}\text { Polishing - } \\
\text { resin } \\
\text { bonded disc }\end{array}$ & 1 & $\begin{array}{l}66 \\
29 \\
99 \\
51\end{array}$ & $\begin{array}{l}\text { Both } \\
\text { Both } \\
\text { Both } \\
\text { Both }\end{array}$ & $\begin{array}{l}\text { ND (ND) } \\
{[430](N D)} \\
{[120](24)} \\
\text { ND (ND) }\end{array}$ & $\begin{array}{l}\text { ND } \\
\text { ND } \\
{[29]} \\
\text { ND }\end{array}$ \\
\hline $\begin{array}{l}\text { Polishing - } \\
\text { resin } \\
\text { bonded disc }\end{array}$ & 1 & $\begin{array}{l}58 \\
87 \\
79 \\
70\end{array}$ & $\begin{array}{c}\text { Both } \\
\text { Both } \\
\text { Engineered quartz } \\
\text { Both }\end{array}$ & $\begin{array}{l}\text { ND (ND) } \\
{[140](27)} \\
\text { ND (ND) } \\
\text { ND (ND) }\end{array}$ & $\begin{array}{c}\text { ND } \\
{[39]} \\
52 \\
{[38]}\end{array}$ \\
\hline $\begin{array}{l}\text { Polishing - } \\
\text { resin } \\
\text { bonded disc }\end{array}$ & 1 & $\begin{array}{l}51 \\
87 \\
96\end{array}$ & $\begin{array}{l}\text { Both } \\
\text { Both } \\
\text { Both }\end{array}$ & $\begin{array}{l}\text { ND (ND) } \\
{[170](11)} \\
{[150](25)}\end{array}$ & $\begin{array}{l}\text { ND } \\
{[19]} \\
{[38]}\end{array}$ \\
\hline $\begin{array}{l}\text { Polishing - } \\
\text { resin } \\
\text { bonded disc }\end{array}$ & 2 & $\begin{array}{l}113 \\
65 \\
42 \\
70\end{array}$ & $\begin{array}{c}\text { Both } \\
\text { Both } \\
\text { Granite } \\
\text { Engineered quartz }\end{array}$ & $\begin{array}{l}\text { ND (ND) } \\
\text { ND (ND) } \\
\text { ND (ND) } \\
\text { ND (ND) }\end{array}$ & $\begin{array}{l}\text { ND } \\
{[22]} \\
\text { ND } \\
{[31]}\end{array}$ \\
\hline $\begin{array}{l}\text { Polishing - } \\
\text { resin } \\
\text { bonded disc }\end{array}$ & 2 & $\begin{array}{l}118 \\
62 \\
61 \\
63\end{array}$ & $\begin{array}{c}\text { Both } \\
\text { Both } \\
\text { Granite } \\
\text { Engineered quartz }\end{array}$ & $\begin{array}{l}\text { ND (ND) } \\
{[190](29)} \\
\text { ND (ND) } \\
\text { ND (ND) }\end{array}$ & $\begin{array}{l}\text { ND } \\
{[57]} \\
N D \\
{[30]}\end{array}$ \\
\hline $\begin{array}{l}\text { Polishing - } \\
\text { resin } \\
\text { bonded disc }\end{array}$ & 2 & $\begin{array}{l}46 \\
80 \\
49 \\
41 \\
77\end{array}$ & $\begin{array}{l}\text { Engineered quartz } \\
\text { Granite } \\
\text { Engineered quartz } \\
\text { Engineered quartz } \\
\text { Both }\end{array}$ & $\begin{array}{l}{[310](34)} \\
{[150](N D)} \\
{[250](37)} \\
{[420](34)} \\
{[160](15)}\end{array}$ & $\begin{array}{c}110 \\
N D \\
93 \\
140 \\
{[24]}\end{array}$ \\
\hline $\begin{array}{l}\text { Grinding - } \\
\text { diamond } \\
\text { cup wheel }\end{array}$ & 2 & $\begin{array}{l}61 \\
66\end{array}$ & $\begin{array}{l}\text { Both } \\
\text { Both }\end{array}$ & $\begin{array}{l}{[550](25)} \\
{[290](33)}\end{array}$ & $\begin{array}{c}140 \\
97\end{array}$ \\
\hline $\begin{array}{l}\text { Grinding - } \\
\text { diamond } \\
\text { cup wheel }\end{array}$ & 2 & $\begin{array}{l}61 \\
61\end{array}$ & $\begin{array}{l}\text { Both } \\
\text { Both }\end{array}$ & $\begin{array}{l}{[470](21)} \\
{[200](25)}\end{array}$ & $\begin{array}{c}97 \\
{[50]}\end{array}$ \\
\hline
\end{tabular}

*The minimum detectable concentrations of respirable dust ranged from $100 \mu \mathrm{g} / \mathrm{m}^{3}$ to $400 \mu \mathrm{g} / \mathrm{m}^{3}$, while the minimum quantifiable concentrations of respirable dust ranged from $320 \mu \mathrm{g} / \mathrm{m}^{3}$ to $1300 \mu \mathrm{g} / \mathrm{m}^{3}$.

†The minimum detectable concentrations of crystalline silica ranged from $10 \mu \mathrm{g} / \mathrm{m}^{3}$ to $40 \mu \mathrm{g} / \mathrm{m}^{3}$, while the minimum quantifiable concentrations of respirable dust ranged from $34 \mu \mathrm{g} / \mathrm{m}^{3}$ to $140 \mu \mathrm{g} / \mathrm{m}^{3}$.

[ ] = Concentrations in brackets are between the minimum detectable and minimum quantifiable concentrations and have more uncertainty associated with them. 


\section{Appendix B: Occupational Exposure Limits and Health Effects}

NIOSH investigators refer to mandatory (legally enforceable) and recommended OELs for chemical, physical, and biological agents when evaluating workplace hazards. OELs have been developed by federal agencies and safety and health organizations to prevent adverse health effects from workplace exposures. Generally, OELs suggest levels of exposure that most employees may be exposed to for up to 10 hours per day, 40 hours per week, for a working lifetime, without experiencing adverse health effects. However, not all employees will be protected if their exposures are maintained below these levels. Some may have adverse health effects because of individual susceptibility, a pre-existing medical condition, or a hypersensitivity (allergy). In addition, some hazardous substances act in combination with other exposures, with the general environment, or with medications or personal habits of the employee to produce adverse health effects. Most OELs address airborne exposures, but some substances can be absorbed directly through the skin and mucous membranes.

Most OELs are expressed as a TWA exposure. A TWA refers to the average exposure during a normal 8- to 10-hour workday. Some chemical substances and physical agents have recommended short term exposure limit or ceiling values. Unless otherwise noted, the short term exposure limit is a 15-minute TWA exposure. It should not be exceeded at any time during a workday. The ceiling limit should not be exceeded at any time.

In the United States, OELs have been established by federal agencies, professional organizations, state and local governments, and other entities. Some OELs are legally enforceable limits; others are recommendations.

- The U.S. Department of Labor OSHA PELs (29 CFR 1910 [general industry]; 29 CFR 1926 [construction industry]; and 29 CFR 1917 [maritime industry]) are legal limits. These limits are enforceable in workplaces covered under the Occupational Safety and Health Act of 1970.

- NIOSH RELs are recommendations based on a critical review of the scientific and technical information and the adequacy of methods to identify and control the hazard. NIOSH RELs are published in the NIOSH Pocket Guide to Chemical Hazards [NIOSH 2010]. NIOSH also recommends risk management practices (e.g., engineering controls, safe work practices, employee education/training, PPE, and exposure and medical monitoring) to minimize the risk of exposure and adverse health effects.

- Other OELs commonly used and cited in the United States include the TLVs, which are recommended by ACGIH, a professional organization, and the workplace environmental exposure levels (WEELs), which are recommended by the American Industrial Hygiene Association, another professional organization. The TLVs and WEELs are developed by committee members of these associations from a review of the published, peer-reviewed literature. These OELs are not consensus standards. TLVs are considered voluntary exposure guidelines for use by industrial hygienists and others trained in this discipline "to assist in the control of health hazards" [ACGIH 2015]. 
WEELs have been established for some chemicals "when no other legal or authoritative limits exist" [AIHA 2015].

Outside the United States, OELs have been established by various agencies and organizations and include legal and recommended limits. The Institut für Arbeitsschutz der Deutschen Gesetzlichen Unfallversicherung (Institute for Occupational Safety and Health of the German Social Accident Insurance) maintains a database of international OELs from European Union member states, Canada (Québec), Japan, Switzerland, and the United States. The database, available at http://www.dguv.de/ifa/GESTIS/GESTIS-Internationale-Grenzwerte-fürchemische-Substanzen-limit-values-for-chemical-agents/index-2.jsp, contains international limits for more than 1,500 hazardous substances and is updated periodically.

OSHA requires an employer to furnish employees a place of employment free from recognized hazards that cause or are likely to cause death or serious physical harm [Occupational Safety and Health Act of 1970 (Public Law 91-596, sec. 5(a)(1))]. This is true in the absence of a specific OEL. It also is important to keep in mind that OELs may not reflect current health-based information.

When multiple OELs exist for a substance or agent, NIOSH investigators generally encourage employers to use the lowest OEL when making risk assessment and risk management decisions. NIOSH investigators also encourage use of the hierarchy of controls approach to eliminate or minimize workplace hazards. This includes, in order of preference, the use of (1) substitution or elimination of the hazardous agent, (2) engineering controls (e.g., local exhaust ventilation, process enclosure, dilution ventilation), (3) administrative controls (e.g., limiting time of exposure, employee training, work practice changes, medical surveillance), and (4) PPE (e.g., respiratory protection, gloves, eye protection, hearing protection). Control banding, a qualitative risk assessment and risk management tool, is a complementary approach to protecting employee health. Control banding focuses on how broad categories of risk should be managed. Information on control banding is available at http://www.cdc.gov/niosh/topics/ctrlbanding/. This approach can be applied in situations where OELs have not been established or can be used to supplement existing OELs.

\section{Respirable Crystalline Silica}

Silica, or silicon dioxide, occurs in a crystalline or noncrystalline (amorphous) form. In crystalline silica, the silicon dioxide molecules are oriented in a fixed pattern versus the random arrangement of the amorphous form. The more common crystalline forms in workplace environments are quartz and cristobalite, and to a lesser extent, tridymite. Occupational exposures to respirable crystalline silica (quartz and cristobalite) have been associated with silicosis, lung cancer, pulmonary tuberculosis disease, and other airway diseases.

Silicosis is an irreversible but preventable fibrotic disease of the lung caused by the deposition of fine crystalline silica particles in the lungs. Silicosis is caused by the inhalation and deposition of crystalline silica particles that are 10 micrometers or less in diameter. Particles 10 micrometers and below are considered respirable particles and have the potential to reach the lower portions of the human lung (alveolar region). Although particle sizes 10 micrometers and below are considered respirable, some of these particles can be deposited 
before they reach the alveolar region [Hinds 1999].

Symptoms of silicosis usually develop insidiously, with cough, shortness of breath, chest pain, weakness, wheezing, and nonspecific chest illnesses. Silicosis usually occurs after years of exposure (chronic), but may appear in a shorter period of time (acute) if exposure concentrations are very high. Acute silicosis is typically associated with a history of high exposures from tasks that produce small particles of airborne dust with a high silica content [NIOSH 1986]. Even though the carcinogenicity of crystalline silica in humans has been strongly debated in the scientific community, the International Agency for Research on Cancer in 1996 concluded that there was "sufficient evidence in humans for the carcinogenicity of inhaled crystalline silica in the form of quartz or cristobalite from occupational sources" [IARC 1997]. Several other serious diseases from occupational exposure to crystalline silica include lung cancer and noncarcinogenic disorders such as immunologic disorders and autoimmune diseases, rheumatoid arthritis, renal diseases, and an increased risk of developing tuberculosis disease after exposure to the infectious agent [NIOSH 2002].

When proper practices are not followed or controls are not maintained, respirable crystalline silica exposures can exceed the OSHA PEL, NIOSH REL, or the ACGIH TLV. For general industry, the OSHA PEL for respirable dust containing $1 \%$ or more of quartz is calculated by dividing 10 milligrams per cubic meter by the percent quartz in the sample, plus two [OSHA $2015 \mathrm{~b}$ ]. For pure (100\%) quartz silica, the PEL is approximately equal to $100 \mu \mathrm{g} / \mathrm{m}^{3}$ of air [OSHA 2015a]. OSHA is in the final stage of rulemaking for an updated, comprehensive standard regarding exposure to crystalline silica. In 2013, OSHA proposed a new PEL of $50 \mu \mathrm{g} / \mathrm{m}^{3}$; OSHA's timetable calls for release of the final rule in 2016 . NIOSH recommends an exposure limit of $50 \mu \mathrm{g} / \mathrm{m}^{3}$ as a TWA for up to a 10-hour work day to reduce the risk of developing silicosis, lung cancer, and other adverse health effects [NIOSH 2010]. The ACGIH TLV for quartz is $25 \mu \mathrm{g} / \mathrm{m}^{3}$ as an 8-hour TWA [ACGIH 2015]. 


\section{References}

ACGIH [2015]. 2015 TLVs ${ }^{\circledR}$ and BEIs ${ }^{\circledR}$ : threshold limit values for chemical substances and physical agents and biological exposure indices. Cincinnati, OH: American Conference of Governmental Industrial Hygienists.

AIHA [2015]. AIHA 2015 Emergency response planning guidelines (ERPG) \& workplace environmental exposure levels (WEEL) handbook. Fairfax, VA: American Industrial Hygiene Association.

Brief R, Scala R [1975]. Occupational exposure limits for novel work schedules. Am Ind Hyg Assoc J 36(6):467-469.

Brown T [2009]. Silica exposure, smoking, silicosis and lung cancer-complex interactions. Occupational medicine 59(2):89-95.

CDC [2015]. Notes from the field: silicosis in a countertop fabricator - Texas, 2014. MMWR 64(5):129-130.

CFR. Code of Federal Regulations. Washington, DC: U.S. Government Printing Office, Office of the Federal Register.

Cooper JH, Johnson DL, Phillips ML [2015]. Respirable silica dust suppression during artificial stone countertop cutting. Ann Occup Hyg 59(1):122-126.

Hankinson JL, Odencrantz JR, Fedan KB [1999]. Spirometric reference values from a sample of the general US population. Am J Respir Crit Care Med 159(1):179-187.

Hinds WC [1999]. Aerosol technology: properties, behavior, and measurements of airborne particles. 2nd ed. New York: John Wiley \& Sons, Inc., pp. 239-242.

IARC [1997]. IARC monographs on the evaluation of the carcinogenic risk of chemicals to humans. Lyons France: World Health Organization, International Agency for Research on Cancer, pp 41-49. [http://monographs.iarc.fr/ENG/Monographs/vol68/volume68.pdf]. Date accessed: March 2016.

Miller MR, Hankinson J, Brusasco V, Burgos F, Casaburi R, Coates A, Crapo R, Enright P, van der Grinten CP, Gustafsson P, Jensen R, Johnson DC, MacIntyre N, McKay R, Navajas D, Pedersen OF, Pellegrino R, Viegi G, Wanger J; ATS/ERS Task Force [2005]. Standardisation of spirometry. Eur Respir J 26(2):319-338.

NIOSH [1986]. Occupational respiratory diseases. Merchant JA, Boehlecke BA, Taylor G, Picket-Harner M. Cincinnati, OH: U.S. Department of Health and Human Services, Centers for Disease Control, National Institute for Occupational Safety and Health, DHHS (NIOSH) Publication No. 1986-102. [http://www.cdc.gov/niosh/docs/86-102/86-102.pdf]. Date accessed: March 2016. 
NIOSH [2002]. NIOSH hazard review: health effects of occupational exposure to respirable crystalline silica. Cincinnati, OH: U.S. Department of Health and Human Services, Centers for Disease Control and Prevention, National Institute for Occupational Safety and Health, DHHS (NIOSH) Publication No. 2002-129. [http://www.cdc.gov/niosh/docs/2002-129/ pdfs/2002-129.pdf]. Date accessed: March 2016.

NIOSH [2010]. NIOSH pocket guide to chemical hazards. Cincinnati, OH: U.S. Department of Health and Human Services, Centers for Disease Control and Prevention, National Institute for Occupational Safety and Health, DHHS (NIOSH) Publication No. 2010-168c. [http://www.cdc.gov/niosh/npg/]. Date accessed: March 2016.

NIOSH [2015]. Workplace safety and health topics: silica. [http://www.cdc.gov/niosh/topics/ silica/]. Date accessed: March 2016.

NIOSH [2016]. NIOSH manual of analytical methods (NMAM®). 4th ed. Schlecht PC, O'Connor PF, eds. Cincinnati, OH: U.S. Department of Health and Human Services, Centers for Disease Control and Prevention, National Institute for Occupational Safety and Health, DHHS (NIOSH) Publication 94-113 (August 1994); 1st Supplement Publication 96-135; 2nd Supplement Publication 98-119; 3rd Supplement 2003-154. [http://www.cdc.gov/niosh/ docs/2003-154/].

OSHA [2002]. Crystalline silica exposure health hazard information for general industry employees. [https://www.osha.gov/Publications/osha3176.html]. Date accessed: March 2016.

OSHA [2014]. OSHA $300 \log$ and the summary of work-related Injuries and illnesses. [https://www.osha.gov/recordkeeping2014/records.html]. Date accessed: March 2016.

OSHA [2015a]. OSHA - NIOSH hazard alert: worker exposure to silica during countertop manufacturing, finishing and installation. [https://www.osha.gov/Publications/OSHA3768. pdf]. Date accessed: March 2016.

OSHA [2015b]. OSHA permissible exposure limits for silica. U.S. Department of Labor, Occupational Safety and Health Administration. [https://www.osha.gov/dsg/etools/silica/ compare to limit/pel/pel.html]. Date accessed: March 2016.

Phillips ML, Johnson DL, Johnson AC [2013]. Determinants of respirable silica exposure in stone countertop fabrication: a preliminary study. J Occup Environ Hyg 10(7):368-373.

Simcox NJ, Lofgren D, Leons J, Camp J [1999]. Silica exposure during granite countertop fabrication. Appl Occup Environ Hyg 14(9):577-582. 
Keywords: North American Industry Classification System 327991 (Cut Stone and Stone Product Manufacturing), Texas, crystalline silica, silicosis, granite, engineered stone, countertops, ventilation 
This page left intentionally blank 
The Health Hazard Evaluation Program investigates possible health hazards in the workplace under the authority of the Occupational Safety and Health Act of 1970 (29 U.S.C. § 669(a) (6)). The Health Hazard Evaluation Program also provides, upon request, technical assistance to federal, state, and local agencies to investigate occupational health hazards and to prevent occupational disease or injury. Regulations guiding the Program can be found in Title 42, Code of Federal Regulations, Part 85; Requests for Health Hazard Evaluations (42 CFR Part 85).

\section{Disclaimer}

The recommendations in this report are made on the basis of the findings at the workplace evaluated and may not be applicable to other workplaces.

Mention of any company or product in this report does not constitute endorsement by NIOSH.

Citations to Web sites external to NIOSH do not constitute NIOSH endorsement of the sponsoring organizations or their programs or products. NIOSH is not responsible for the content of these Web sites. All Web addresses referenced in this document were accessible as of the publication date.

\section{Acknowledgments}

Analytical Support: Bureau Veritas North America

Desktop Publisher: Shawna Watts

Editor: Ellen Galloway

Logistics: Donnie Booher, Kevin Moore

Medical Field Assistance: Marie de Perio, Rini Mathew

Spanish Interpretation: Emily Hall, Betsy Blanco

\section{Availability of Report}

Copies of this report have been sent to the employer and employees at the facility. The state and local health department and the Occupational Safety and Health Administration Regional Office have also received a copy. This report is not copyrighted and may be freely reproduced.

This report is available at http:/www.cdc.gov/niosh/hhe/reports/pdfs/2014-0215-3250.pdf.

\section{Recommended citation for this report:}

NIOSH [2016]. Health hazard evaluation report: evaluation of crystalline silica exposure during fabrication of natural and engineered stone countertops. By Zwack LM, Victory KR, Brueck SE, Qi C. Cincinnati, OH: U.S. Department of Health and Human Services, Centers for Disease Control and Prevention, National Institute for Occupational Safety and Health, NIOSH HHE Report No. 2014-0215-3250. 
Delivering on the Nation's promise:

Safety and health at work for all people through research and prevention

To receive NIOSH documents or more information about occupational safety and health topics, please contact NIOSH:

Telephone: 1-800-CDC-INFO (1-800-232-4636)

TTY: 1-888-232-6348

CDC INFO: www.cdc.gov/info

or visit the NIOSH Web site at www.cdc.gov/niosh

For a monthly update on news at $\mathrm{NIOSH}$, subscribe to

$\mathrm{NIOSH}$ eNews by visiting www.cdc.gov/niosh/eNews. 